\title{
Description and Results of the 2000 NIST/NOAA Interlaboratory Comparison Exercise Program for Organic Contaminants and Trace Elements in Marine Mammal Tissues
}

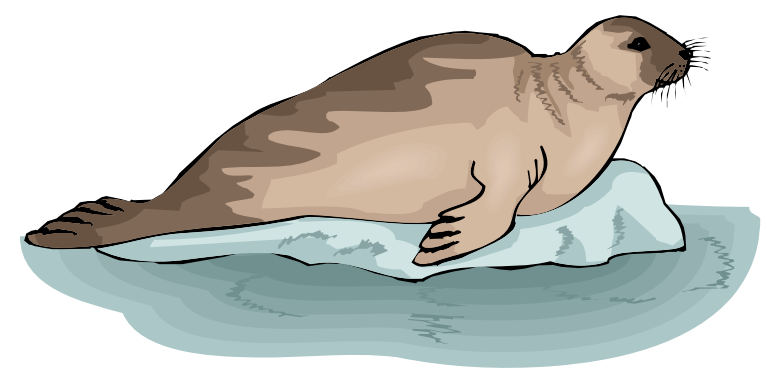

John R. Kucklick

Steven J. Christopher

Paul R. Becker

Rebecca S. Pugh

Barbara J. Porter

Michele M. Schantz

Elizabeth A. Mackey

Stephen A. Wise

Teresa K. Rowles 
NISTIR 6849

\title{
Description and Results of the 2000 NIST/NOAA Interlaboratory Comparison Exercise Program for Organic Contaminants and Trace Elements in Marine Mammal Tissues
}

\author{
John R. Kucklick \\ Steven J. Christopher \\ Paul R. Becker \\ Rebecca S. Pugh \\ Chemical Science and Technology Laboratory \\ Analytical Chemistry Division \\ Charleston Laboratory \\ Barbara J. Porter \\ Michele M. Schantz \\ Elizabeth A. Mackey \\ Stephen A. Wise \\ Chemical Science and Technology Laboratory \\ Analytical Chemistry Division \\ Teresa K. Rowles \\ National Oceanic and Atmospheric Administration \\ National Marine Fisheries Service
}

July 2002

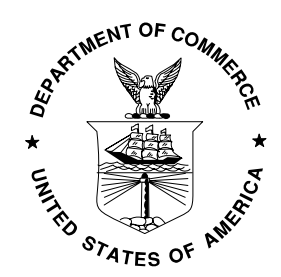

U.S. Department of Commerce Donald L. Evans, Secretary

National Institute of Standards and Technology Arden Bement, Director 


\section{TABLE OF CONTENTS}

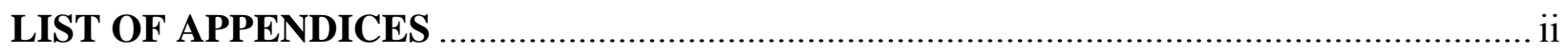

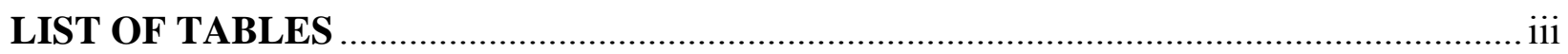

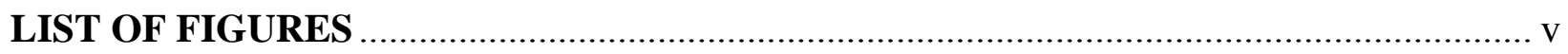

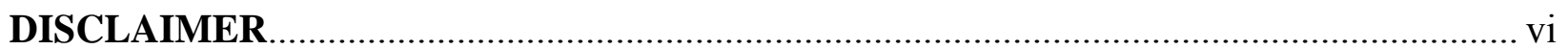

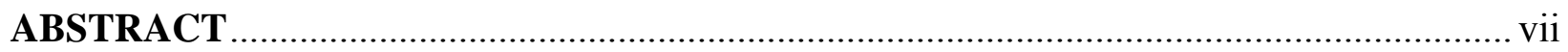

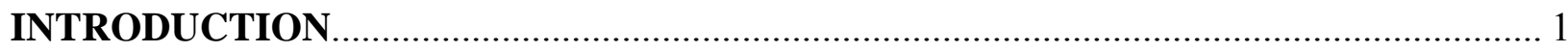

Background on Interlaboratory Comparison Exercises and Associated Quality

Assurance Activities Conducted by NIST for the MMHSRP .......................................... 2

Preparation, Analysis, and Distribution of Control Materials ....................................................... 2

Development of Standard Reference Materials (SRMs) ................................................................... 3

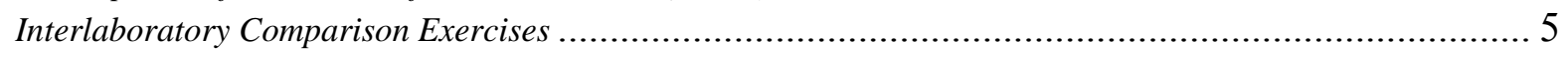

PART 1: DESCRIPTION AND RESULTS OF THE 2000 NIST/NOAA INTERLABORATORY COMPARISON EXERCISE PROGRAM FOR ORGANIC

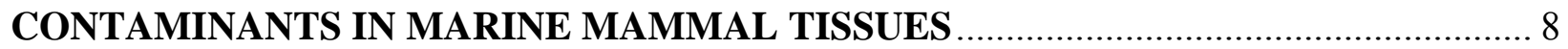

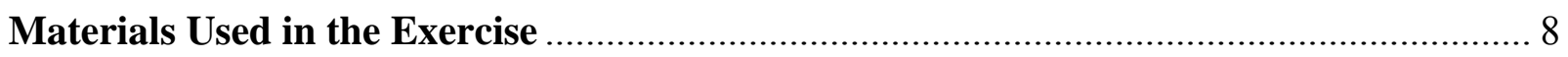

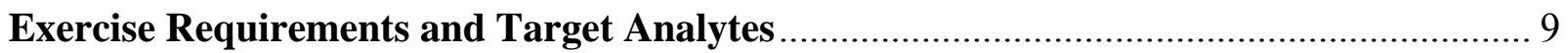

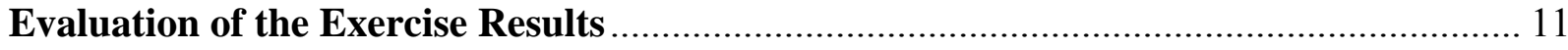

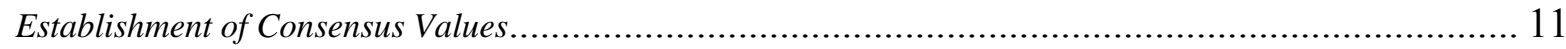

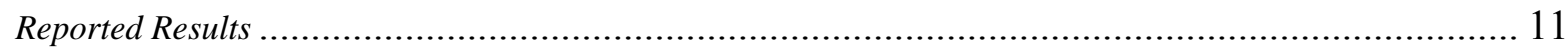

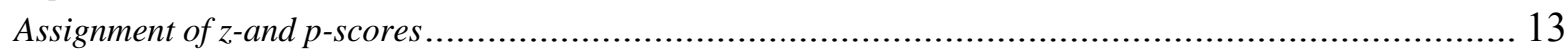

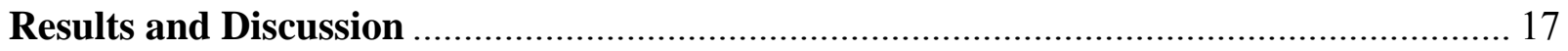

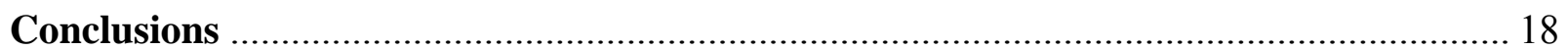

PART 2: DESCRIPTION AND RESULTS OF THE 2000 NIST/NOAA

INTERLABORATORY COMPARISON EXERCISE PROGRAM FOR TRACE

ELEMENTS IN MARINE MAMMAL TISSUES .................................................... 19

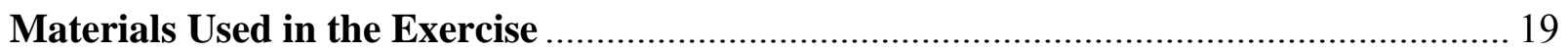

Exercise Requirements and Target Analytes............................................................. 19

Evaluation of the Exercise Results ............................................................................. 19

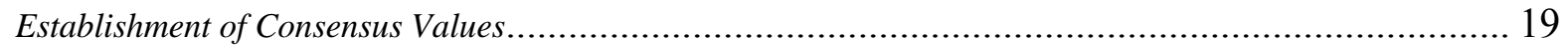

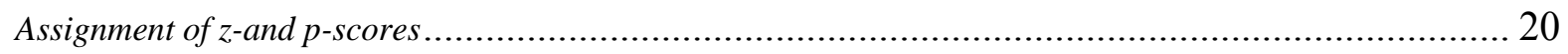

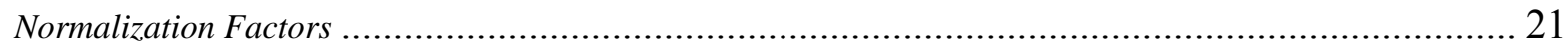

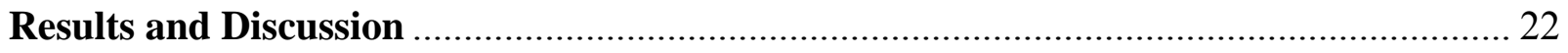

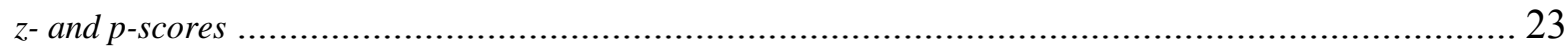

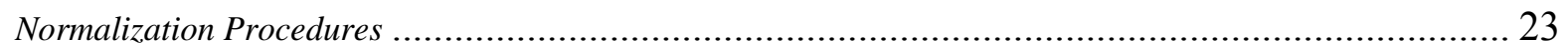

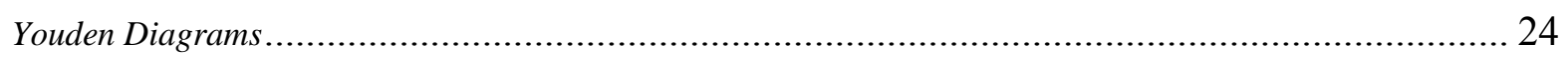

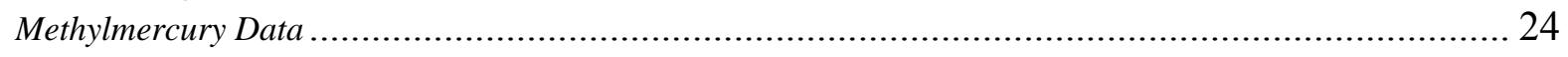

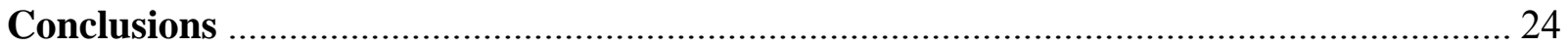

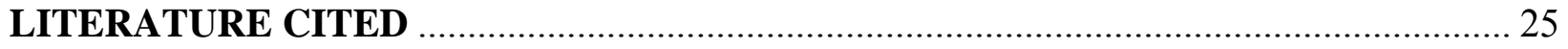




\section{LIST OF APPENDICES}

PART 1: DESCRIPTION AND RESULTS OF THE 2000 NIST/NOAA INTERLABORATORY COMPARISON EXERCISE PROGRAM FOR ORGANIC CONTAMINANTS IN MARINE MAMMAL TISSUES ........................................E

A. Tabular Results by Analyte from Individual Laboratories ............................................A-1-26

B. Graphical Results of PCB Congener and Lipid Data Reported by All

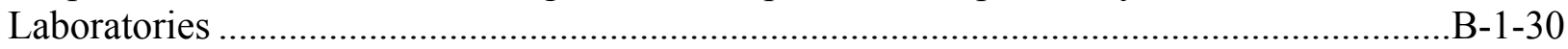

C. Graphical Results of Organochlorine Pesticide Data Reported by All

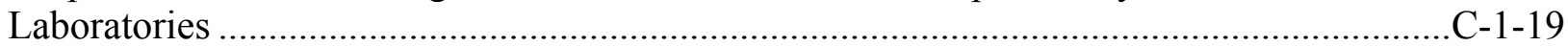

D. Additional Analyte Data Reported by Individual Laboratories ........................................ D-1-6

E. Tabular Summary of Methods Used for Analysis by Each Laboratory..............................E-1-8

PART 2: DESCRIPTION AND RESULTS OF THE 2000 NIST/NOAA INTERLABORATORY COMPARISON EXERCISE PROGRAM FOR TRACE ELEMENTS IN MARINE MAMMAL TISSUES.

F. List of Participants for the Trace Elements Exercise ...................................................

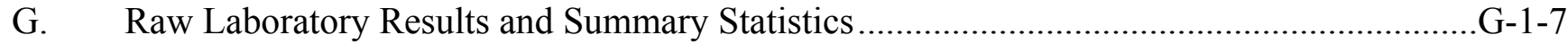

H. Consensus Results and Summary Statistics ...................................................................

I. Consensus Mean Plots for Various Elements in Beluga Whale Liver (QC97LH2) and SRM 1946 Lake Superior Fish Tissue Samples ...................................... $1-6$ Cadmium and Copper in Beluga Whale Liver (QC97LH2) ...............................................

Mercury and Iron in Beluga Whale Liver (QC97LH2) .................................................

Selenium and Arsenic in Beluga Whale Liver (QC97LH2) .............................................

Cadmium and Mercury in SRM 1946 Lake Superior Fish Tissue ..................................... -4

Iron and Selenium in SRM 1946 Lake Superior Fish Tissue ...........................................

Arsenic in SRM 1946 Lake Superior Fish Tissue ..........................................................

J. Evaluation of Laboratory Performance Using z- and p-scores ....................................... $\quad$ - $1-3$

z-score Plot for Beluga Whale Liver (QC97LH2) ....................................................

Z-score Plot for SRM 1946 Lake Superior Fish Tissue ....................................................

K. Accuracy Assessment Using Normalization Factors ....................................................

L. Youden Two-Sample Plots for Pilot Whale Liver (QC91LH1) vs. Beluga

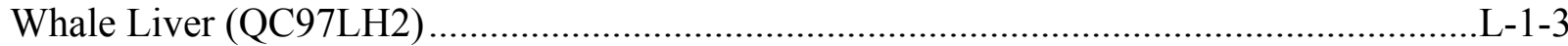

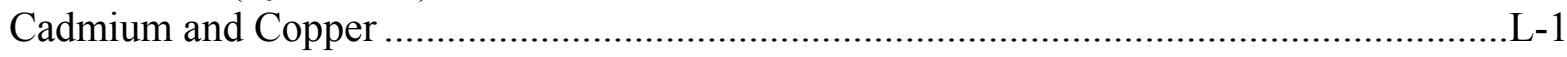

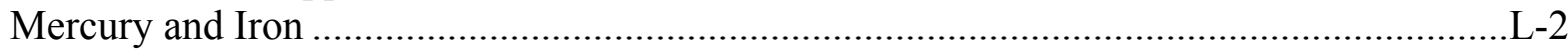

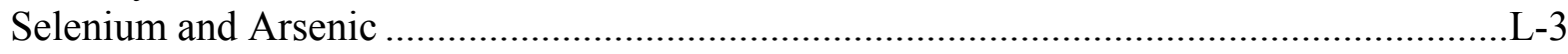




\section{LIST OF TABLES}

Table 1: Interlaboratory Comparison Exercises Conducted for the MMHSRP from 1991-2001

PART 1: DESCRIPTION AND RESULTS OF THE 2000 NIST/NOAA INTERLABORATORY COMPARISON EXERCISE PROGRAM FOR ORGANIC CONTAMINANTS IN MARINE MAMMAL TISSUES

Table 1.1: Laboratories Participating in the NIST/NOAA Interlaboratory Comparison Exercise Program for Organic Contaminants

Table 2.1: Target Analytes for the Second Annual NIST/NOAA Interlaboratory Comparison Exercise Program for Organic Contaminants and Trace Elements in Marine Mammal Tissues

Table 3.1: PCB congeners in Control Material IV (ng/g wet mass) Reported by the Participants the NIST/NOAA Interlaboratory Comparison Exercise Program for Organic Contaminants and Trace Elements in Marine Mammal Tissues.

Table 4.1: Organochlorine Pesticides in Control Material IV (ng/g wet mass) Reported by the Participants in the NIST/NOAA Interlaboratory Comparison Exercise Program for Organic Contaminants and Trace Elements in Marine Mammal Tissues .

Table 5.1: PCB Congeners in SRM 1945 (ng/g wet mass) Reported by the Participants in the NIST/NOAA Interlaboratory Comparison Exercise Program for Organic Contaminants and Trace Elements in Marine Mammal Tissues.

Table 6.1: Organochlorine Pesticides in SRM 1945 (ng/g wet mass) Reported by the Participants in the NIST/NOAA Interlaboratory Comparison Exercise Program for Organic Contaminants and Trace Elements in Marine Mammal Tissues.

PART 2: DESCRIPTION AND RESULTS OF THE 2000 NIST/NOAA INTERLABORATORY COMPARISON EXERCISE PROGRAM FOR TRACE ELEMENTS IN MARINE MAMMAL TISSUES

Table 2.1: List of Laboratories Participating in the NIST/NOAA Interlaboratory Comparison Exercise Program for Trace Elements.

Table 2.2: Individual Laboratory Results and Summary Statistics $(\mathrm{mg} / \mathrm{kg}$, wet mass) for Various Trace Elements in Pilot Whale Liver (QC91LH1), Beluga Whale Liver (QC97LH2) and SRM 1946 Lake Superior Fish Tissue Samples 
Table 3.2. Laboratory Means and Consensus Mean Summary Statistics $(\mathrm{mg} / \mathrm{kg}$, wet mass) for Various Trace Elements in Pilot Whale Liver (QC91LH1), Beluga Whale Liver (QC97LH2) and SRM 1946 Lake Superior Fish Tissue Samples.

Table 4.2: Laboratory z-scores Computed for Beluga Whale Liver (QC97LH2) and SRM 1946 Lake Superior Fish Tissue Samples.

Table 5.2: Laboratory p-scores Computed for Beluga Whale Liver (QC97LH2) and SRM 1946 Lake Superior Fish Tissue Samples

Table 6.2: Normalization Factors Used to Compute Normalized Laboratory and Consensus Mean Data. $\mathrm{K}-1$

Table 7.2: Laboratory Means and Consensus Mean Summary Statistics (mg/kg, wet mass) Computed After the Application of the Normalization Procedure to Beluga Whale Liver (QC97LH2) and SRM 1946 Lake Superior Fish Tissue Samples ...... 


\section{LIST OF FIGURES}

Figure 2.1: Using Youden Plots for Error Assessment...........................................................24 


\section{DISCLAIMER}

Certain commercial equipment or instruments are identified in this report to specify adequately the experimental procedures. Such identification does not imply recommendations or endorsement by the National Institute of Standards and Technology nor does it imply that the equipment or instruments are the best available for the purpose. 


\begin{abstract}
The National Institute of Standards and Technology (NIST), in support of the National Oceanic and Atmospheric Administration's Marine Mammal Health and Stranding Response Program (NOAA/MMHSRP) conducts annual interlaboratory comparison exercises for the determination of chlorinated pesticides, polychlorinated biphenyl congeners, and trace elements in marine mammal tissues. These exercises provide one mechanism for laboratories to evaluate their measurement quality and comparability for these constituents in marine mammal tissues. Results of the 2000 NIST/NOAA/MMHSRP Interlaboratory Comparison Exercise Program for Organic Contaminants and Trace Elements in Marine Mammal Tissues are presented in two parts in this report, after a brief historical introduction of the program. Part 1 focuses on the development and analytical results of the organic contaminant component of this exercise, while Part 2 describes the features and analytical results for the trace elements component. For the organic contaminant exercise, 13 laboratories determined the concentrations of selected polychlorinated biphenyl congeners (PCBs) and organochlorine pesticides in a homogenized blubber control material "Marine Mammal Quality Assurance Exercise Control Material IV" (Control Material IV) and Standard Reference Material (SRM) 1945 Organics in Whale Blubber. Seven laboratories participated in the 2000 trace element exercise, where each laboratory performed measurements on a suite of elements $(\mathrm{Cu}, \mathrm{Cd}, \mathrm{Pb}, \mathrm{Fe}, \mathrm{Se}, \mathrm{As}, \mathrm{Hg}, \mathrm{Ni}, \mathrm{Ag}$, and $\mathrm{Zn})$ in three NIST quality assurance materials: Pilot Whale Liver Homogenate I (QC91LH1), Beluga Whale Liver Homogenate II (QC97LH2), and candidate SRM 1946 Lake Superior Fish Tissue. This report includes the results reported by the participating laboratories, combined consensus data results, and summary statistics for each analyte in the samples. The numerical indices used to assess laboratory performance are also discussed.
\end{abstract}




\section{INTRODUCTION}

Laboratories measuring contaminants in the marine environment must assess the accuracy and precision of their measurements. Quality control of measurements made on marine environmental samples is vital to the accurate assessment of marine pollution and its effects on wildlife and human health. Often, reference materials are limited or not available for many marine matrices of interest (e.g., marine mammal tissues and marine fish). Consequently, marine resource management decisions may be based on subjective analytical results leading to potential environmental, health, or economic consequences. The National Institute of Standards and Technology's (NIST's) Analytical Chemistry Division has several programs to assess the data quality of laboratories and agencies performing chemical measurements on marine-related samples. NIST's reference material production, interlaboratory comparison exercises, and environmental specimen banking all contribute to the accuracy of chemical measurements in the marine environment.

NIST helps benchmark and improve the quality of analytical data gathered on the marine environment by administering annual interlaboratory comparison exercises. The largest exercise was initiated in 1987 and funded in part until 2000 by the National Oceanic and Atmospheric Administration (NOAA) National Status and Trends Marine Monitoring Program (NOAA/NS\&T) (Cantillo and Parris, 1990, 1993; Cantillo 1995; Schantz et al., 1999). NIST provides mechanisms for assessing the interlaboratory and temporal comparability of data and for improving measurements of polycyclic aromatic hydrocarbons, polychlorinated biphenyl (PCB) congeners, and chlorinated pesticides in bivalve mollusk, sediment, and fish samples. In addition, the National Research Council of Canada, with support from NOAA, administers a similar interlaboratory comparison exercise for trace elements in marine environmental materials. The NIST program for organic contaminants includes developing improved analytical methods, producing NIST Standard Reference Materials (SRMs) and other control materials, conducting annual interlaboratory comparison exercises, and coordinating workshops to discuss exercise results, thus providing a cooperative problem-solving forum for the participants. This program continues as the NIST Intercomparison Program for Organic Contaminants in the Marine Environment with partial support from fees paid by the participants.

Through the NIST National Marine Analytical Quality Assurance Program and with support from the NOAA Marine Mammal Health and Stranding Response Program (MMHSRP), the interlaboratory comparison activities have been expanded to include analyses of marine mammal tissues. The 2000 NIST/NOAA Interlaboratory Comparison Exercise Program for Organic Contaminants and Trace Elements in Marine Mammal Tissues was modeled after the exercises described above. Specifically, this exercise was designed to help laboratories assess data comparability and quality relative to other groups providing measurements of organochlorine contaminants and trace elements in marine mammal tissues and to link these important measurements to a national metrology laboratory. The results of the exercises presented in this report should be useful both for assessing current methodology and reducing the variability of contaminant data reported on marine mammals. Future exercises will allow for the assessment of analytical data quality over time. This report summarizes the results of the 2000 exercise including methods used for analysis, data reported by the laboratories on the intercomparison materials, and numerical indices used to assess laboratory performance. 


\section{Background on Interlaboratory Comparison Exercises and Associated Quality Assurance Activities Conducted by NIST for the MMHSRP}

In 1987, the NOAA National Marine Fisheries Service (NMFS), Office of Protected Resources, established the National Marine Mammal Tissue Bank (NMMTB) as part of the National Biomonitoring Specimen Bank maintained by NIST. The NMMTB was designed for the longterm cryogenic archiving of marine mammal tissue specimens for future retrospective chemical analysis. In 1992, the Marine Mammal Health and Stranding Response Act (Public Law 102587) formally established the NMMTB by legislation. NMFS implemented this Act by instituting the MMHSRP. Components of this program include marine mammal stranding networks, response to unusual mortality events, information management, real-time measurement of tissue contaminants, specimen banking, and analytical quality assurance.

Within the MMHSRP, real-time monitoring of contaminants in marine mammals is conducted by NMFS's Northwest Fisheries Science Center (NWFSC), Environmental Conservation Division. This monitoring includes analyses of samples collected specifically for real-time analysis and subsamples of banked specimens. NIST also analyzes aliquots of banked specimens to establish a baseline of concentration values for comparing with data generated by the NWFSC and other laboratories analyzing these specimens, and to monitor changes in analyte levels during specimen storage. Numerous other laboratories worldwide analyze marine mammal tissues for research and monitoring purposes. To assess the accuracy and comparability of results among NIST, NWFSC, and other laboratories, NIST in collaboration with NMFS developed a quality assurance (QA) program for analytical measurements of contaminants in marine mammal tissues. This QA program, described by Wise (1993), consists of (1) preparation, analysis, and distribution of marine mammal tissue control materials; (2) development of Standard Reference Materials (SRMs) for use in the analysis of marine mammal tissues; and (3) interlaboratory comparison exercises among laboratories analyzing marine mammal tissues.

\section{Preparation, Analysis, and Distribution of Control Materials}

Control materials, which are similar to the matrices being analyzed, are analyzed with regular samples with the results monitored to determine whether the analytical procedures are in control. The first control materials developed for the program were derived from liver and blubber tissues collected from pilot whales (Globicephala melaena) stranded in 1990 on Cape Cod, MA. Approximately $2 \mathrm{~kg}$ of each tissue were used to prepare tissue homogenates for use as analytical control materials and in interlaboratory comparison exercises. These homogenates are fresh frozen samples similar to marine mammal tissue samples routinely analyzed, rather than freezedried matrices frequently used as reference materials. The tissues were cryogenically pulverized and homogenized in Teflon mills to provide frozen powder-like materials (Zeisler et al., 1983). These two control materials were analyzed at NIST to determine concentrations of trace elements (Whale Liver Homogenate I) and organic contaminants (Whale Blubber Control Material) and to assess sample homogeneity (Wise et al., 1993).

The concentrations of 40 trace elements plus methylmercury were determined in the Whale Liver Homogenate I using INAA, differential pulse and square wave stripping voltammetry, cold vapor atomic absorption spectroscopy (CVAAS) for $\mathrm{Hg}$, and ion-exchange chromatography plus 
CVAAS (for methylmercury). Thirty PCB congeners and 16 chlorinated pesticides were determined in the Whale Blubber Control Material using gas chromatography-electron capture detection (GC-ECD) with both DB-5 and C-18 columns and gas chromatography-mass spectrometry (GC-MS) using a DB-5 column. The data resulting from analyses of both control materials, as well as a description of the analytical techniques and interpretation of the results, were published in Wise et al. (1993).

Both the pilot whale liver homogenate (Whale Liver Homogenate I) and the Whale Blubber Control Material have been available for use by laboratories as control materials during the routine analyses of marine mammal tissues. Based on experience gained in the preparation and analyses of Whale Liver Homogenate I, a second liver homogenate control material (Whale Liver Homogenate II ) is being developed from livers collected in 1996 from beluga whales taken in Alaska native subsistence hunts. Whale Liver Homogenate II (fresh-frozen material) was distributed in 1997 to three laboratories participating in the interlaboratory comparison exercise on trace elements in marine mammal liver. This control material was also distributed to seven laboratories participating in the trace element part of the 2000 interlaboratory comparison exercise.

Whale Liver Homogenate II represents a $5 \mathrm{~kg}$ subsample of $30 \mathrm{~kg}$ of beluga whale liver that was originally collected for the development of a marine mammal liver SRM. The Pilot Whale Liver Homogenate I will be nearly exhausted by the end of calendar year 2001 (some portion is being retained for sample stability monitoring); therefore, Whale Liver Homogenate II will be the primary control material used in future analyses for trace elements in marine mammal tissues.

In the 1999 interlaboratory comparison exercise Whale Blubber Control Material was re-labeled Marine Mammal Blubber Control Material III, and distributed as an "unknown" to participants. Because the amount of this control material is now very limited, Whale Blubber Control Material IV is presently being developed as a replacement. Whale Blubber Control Material IV was derived from blubber that was collected by the NMFS Beaufort Laboratory, from a single pilot whale that stranded in 1999 on Pea Island, North Carolina. This material was cryogenically homogenized and labeled, QCO0-WB4 Whale Blubber Control Material IV, and was distributed as an "unknown" to participants in the 2000 interlaboratory comparison exercise for the organic analysis.

\section{Development of Standard Reference Materials (SRMs)}

One of the goals of the marine mammal QA program is to develop certified reference materials (CRMs) for validating analytical measurements of trace elements and organic contaminants in marine mammal tissues. At the beginning of the program, there were several CRMs available from NIST, the National Research Council of Canada (Ottawa, Canada), and the Community Bureau of Reference (Brussels, Belgium) for inorganic contaminants in marine tissues including oyster tissue, mussel tissue, fish muscle and liver tissue, and lobster tomalley. However, for organic contaminants such as PCB congeners and chlorinated pesticides, there were only mussel tissue, SRM 1974 Organics in Mussel Tissue (Mytilus edulis) and cod fish liver oil, SRM 1588 Organics in Cod Liver Oil. SRM 1588, which serves as a suitable surrogate for a tissue extract with a high lipid content, had certified concentrations for 5 PCB congeners and 10 chlorinated 
pesticides and noncertified values for 20 additional PCB congeners and 4 additional chlorinated pesticides (Schantz et al., 1992). This material was reissued in 1998 as SRM 1588a and now has certified or reference values for over 80 organic contaminants. The mussel tissue SRM 1974 was reissued as SRM 1974a and has certified or reference values for over 100 organic and inorganic constituents (Schantz et al., 1997).

Because of the lack of organic reference materials, blubber was selected as the first priority tissue for development of SRMs as part of the marine mammal QA Program. The experience gained from the preparation and analysis of the pilot whale blubber control material (Wise et al., 1993) was used to develop SRM 1945 Organics in Whale Blubber, a certified material that can be used for validating measurements of organic contaminants in marine mammal blubber.

SRM 1945 was prepared from approximately $15 \mathrm{~kg}$ of blubber that was collected in September 1991 from a stranding of pilot whales on Cape Cod, MA. The material was cryogenically pulverized and homogenized in the same manner as described for the control materials. The resulting frozen blubber homogenate was analyzed using three different analytical techniques based on GC-ECD on two stationary phases with different selectivities for the separation of PCB congeners and on GC-MS. The results of these three techniques provided certified concentrations for 27 PCB congeners (PCBs 18, 44, 49, 52, 66, 87, 95, 99, 101/90, 105, 110, $118,128,138 / 163 / 164,149,151,153,156,170 / 190,180,183,187,194,195,201,206$, and 209) and 15 chlorinated pesticides $(\mathrm{HCB}, \alpha-\mathrm{HCH}, \gamma-\mathrm{HCH}$, heptachlor epoxide, oxychlordane, mirex, cis-chlordane, cis-nonachlor, trans-nonachlor, 2,4'-DDE, 4,4'-DDE, 2,4'-DDD, 4,4'-DDD, 2,4' DDT, and 4,4'-DDT). Noncertified values for two additional PCB congeners (PCB 28 and 31) and chlorinated pesticides (dieldrin and $\beta-\mathrm{HCH}$ ) are available.

Analytical data for the certification of PCBs and chlorinated pesticides in SRM 1945 were published by Schantz et al. (1995). SRM 1945, which represents the most highly characterized natural-matrix SRM with respect to these organic compounds, complements the other frozen tissue SRM (e.g., SRM 1974a) by providing concentrations that are generally a factor of 10 to 100 times higher for the PCB congeners and chlorinated pesticides. Solvent extraction of the whale blubber produces an oil matrix similar to that of the cod liver oil SRM; however, the concentrations of PCB congeners and pesticides in SRM 1945 are generally 2 to 3 times lower than the NIST cod liver oil SRM except for the PCB congeners with higher degrees of chlorination, which have concentrations similar to the cod liver oil.

Additional concentration values for constituents not originally measured in SRM 1945 (i.e., dioxins, furans, non-ortho PCBs, and polyhalogenated diphenyl ethers) have been provided for this material by the National Wildlife Research Center, Canadian Wildlife Service (CWS). These data are found in CWS Lab Services Section Reports CHEM-OC-97-40, CHEM-PCDD98-1, and CHEM-PCDD-98-4). SRM 1945 was found to have relatively high amounts of twelve polybrominated diphenyl ethers (tetra through hepta congeners). More recently, measurements have been made by NIST on additional analytes in SRM 1945, including congeners of polychlorinated naphthalenes (PCNs) and co-planar PCBs $(77,126,169)$.

The low relative uncertainties associated with the majority of analyte concentrations (5\% to 10 $\%$ ) and the extensive list of certified analytes makes SRM 1945 a valuable resource for 
validating analytical methods for the determination of halogenated compounds in marine mammal blubber and other high lipid-containing materials.

\section{Interlaboratory Comparison Exercises}

An interlaboratory comparison made on common, well-homogenized reference samples is one method to assess and improve data comparability. Such exercises currently involve the analysis of an unknown sample, a control material, and a NIST-traceable SRM by the participants. A list of analytes to be compared among the laboratories is provided to the participants. Participants submit their results to the NIST coordinator who evaluates data comparability using the performance measures recommended by the International Union of Pure and Applied Chemistry (IUPAC, 1993). Reports on the comparability evaluation are provided to the participants. NIST then conducts a workshop with the participants to discuss the results and ways to improve comparability.

Table 1 summarizes several important aspects of the interlaboratory comparison exercises conducted from 1991 to date, including target analytes, matrix samples, and the number of participating laboratories. The first exercise was conducted in 1991-92 and consisted of the distribution of the liver and blubber control materials to NWFSC and several other laboratories for analysis, i.e., Department of Fisheries and Oceans (DFO) Canada in Winnipeg, the Geochemical and Environmental Research Group (GERG) at Texas A\&M University, and the Department of Analytical and Environmental Chemistry at the University of Ulm in Germany.

In 1992, three laboratories (NIST, DFO Canada in Winnipeg, and the Department of Analytical and Environmental Chemistry at the University of Ulm in Germany) analyzed blubber subsamples from four to six beluga whales, the pilot whale blubber control material, and SRM 1588 in an interlaboratory exercise to compare results of analyses for PCB congeners and chlorinated pesticides. The analytical methods used by these three laboratories are described in Schantz et al. (1996). To minimize variability resulting from the source of calibration solutions, all three laboratories used common solutions to prepare calibration standards. Different internal standards and volume correction standards were used by each laboratory. Each laboratory used its preferred methods of extraction (Soxhlet extraction at NIST, ball-milling extraction at DFO, and column extraction at Ulm). All three laboratories used a size-exclusion chromatography cleanup, but with different columns, to remove the lipid material from the extracts and separated the PCB congeners from the majority of the pesticides as part of the cleanup procedures. GCECD was used by all three laboratories for the final analysis employing different columns. The results of this exercise were published in Schantz et al. (1996). 
Table 1: Interlaboratory comparison exercises conducted for the MMHSRP from 1991-2001.

\begin{tabular}{|c|c|c|c|c|}
\hline Dates & Analytes & Matrices & Objective & Participants \\
\hline \multirow[t]{2}{*}{$1991-92$} & $\begin{array}{l}\mathrm{PCBs} / \mathrm{Cl} \\
\text { pesticides }^{1}\end{array}$ & Whale blubber & $\begin{array}{l}\text { Laboratory } \\
\text { comparability }\end{array}$ & $\begin{array}{l}\text { NIST;NWFSC;DFO }{ }^{3} \text { Canada; } \\
\text { Texas A\&M Univ.; Univ. Ulm }\end{array}$ \\
\hline & $\begin{array}{l}\text { Trace } \\
\text { Elements }\end{array}$ & Whale liver $\mathrm{CM}^{2}$ & Analytical control & NIST;NWFSC \\
\hline 1992-93 & $\begin{array}{l}\mathrm{PCBs} / \mathrm{Cl} \\
\text { pesticides }\end{array}$ & $\begin{array}{l}\text { Whale blubber; } \\
\text { whale blubber CM }\end{array}$ & $\begin{array}{l}\text { Laboratory } \\
\text { comparability }\end{array}$ & NIST; DFO Canada; Univ. Ulm \\
\hline 1993-1994 & PCBs & $\begin{array}{l}\text { Whale blubber; } \\
\text { whale blubber } \mathrm{CM}\end{array}$ & $\begin{array}{l}\text { SRM } \\
\text { development }\end{array}$ & $\begin{array}{l}\text { NIST;NWFSC; DFO Canada; Texas } \\
\text { A\&M Univ.; Arthur D. Little; NW } \\
\text { Aquatic Sciences; Univ. Ulm }\end{array}$ \\
\hline 1993-1997 & $\begin{array}{l}\mathrm{PCBs} / \mathrm{Cl} \\
\text { pesticides } \\
\text { and Trace } \\
\text { Elements }\end{array}$ & Whale / seal liver & $\begin{array}{l}\text { Sample } \\
\text { comparability }\end{array}$ & NIST; NWFSC \\
\hline 1997-1998 & $\begin{array}{l}\text { Trace } \\
\text { Elements }\end{array}$ & Whale liver & $\begin{array}{l}\text { Laboratory } \\
\text { comparability and } \\
\text { CM development }\end{array}$ & $\begin{array}{l}\text { NIST;NWFSC; Texas A\&M Univ., } \\
\text { Veterinary College }\end{array}$ \\
\hline 1999 & $\begin{array}{l}\mathrm{PCBs} / \mathrm{Cl} \\
\text { Pesticides }\end{array}$ & $\begin{array}{l}\text { SRM } 1945 \text { Organics } \\
\text { in Whale Blubber }\end{array}$ & $\begin{array}{l}\text { Laboratory } \\
\text { comparability }\end{array}$ & 10 laboratories \\
\hline 2000 & $\begin{array}{l}\mathrm{PCBs} / \mathrm{Cl} \\
\text { Pesticides }\end{array}$ & $\begin{array}{l}\text { Whale blubber CM } \\
\text { SRM } 1945 \text { Organics } \\
\text { in Whale Blubber }\end{array}$ & $\begin{array}{l}\text { Laboratory } \\
\text { comparability and } \\
\text { program } \\
\text { expansion }\end{array}$ & 13 laboratories (organics) \\
\hline \multirow{4}{*}{$\begin{array}{l}2001 \\
\text { (projected) }\end{array}$} & $\begin{array}{l}\text { Trace } \\
\text { Elements }\end{array}$ & $\begin{array}{l}\text { Whale Livers } \\
\text { (QC91LH1) } \\
\text { (QC97LH2) } \\
\text { SRM 1946 Lake } \\
\text { Superior Fish Tissue }\end{array}$ & & 7 laboratories (trace elements) \\
\hline & $\begin{array}{l}\mathrm{PCBs} / \mathrm{Cl} \\
\text { Pesticides }\end{array}$ & $\begin{array}{l}\text { SRM } 1945 \text { and } \\
\text { Whale blubber CM }\end{array}$ & $\begin{array}{l}\text { Laboratory } \\
\text { comparability and } \\
\text { program } \\
\text { expansion }\end{array}$ & 21 laboratories (organics) ${ }^{4}$ \\
\hline & $\begin{array}{l}\text { Trace } \\
\text { Elements }\end{array}$ & $\begin{array}{l}\text { Whale Livers } \\
\text { (QC91LH1) } \\
\text { (QC97LH2) }\end{array}$ & & 31 laboratories (trace elements) ${ }^{4}$ \\
\hline & & $\begin{array}{l}\text { Candidate } \\
\text { SRM } 1947 \text { Lake } \\
\text { Michigan Fish Tissue }\end{array}$ & & \\
\hline
\end{tabular}

${ }^{1}$ Chlorinated pesticides

${ }^{2}$ Control material

${ }^{3}$ Department of Fisheries and Oceans

${ }^{4}$ Projected number of laboratories based on jars of material shipped to participants 
In 1993, two intercomparison exercises were initiated. The first exercise focused on determining PCB congeners and chlorinated pesticides in blubber tissue using the blubber homogenate prepared as a proposed SRM (see discussion above). This material was distributed to NWFSC and several other laboratories for analysis (i.e., DFO Canada, GERG, Northwestern Aquatic Sciences in Newport, OR, Arthur D. Little in Cambridge, MA, and University of Ulm). The second QA activity involved a "sample split" between NIST and NWFSC of blubber and liver samples from three marine mammals for both inorganic and organic analyses. These tissue samples were from specimens collected as part of the tissue banking and monitoring components of the program. In the past, for many of the liver and blubber specimens in the NMMTB, similar tissue samples were collected using NWFSC protocols and shipped to NWFSC for analysis as part of the monitoring effort. For this intercomparison exercise, NIST homogenized the selected liver and blubber samples from the tissue bank and provided a subsample of each homogenate to NWFSC. NIST and NWFSC analyzed tissue homogenate subsamples from the bank (liver for trace elements and blubber for PCBs and pesticides). The NWFSC analyzed the "monitoring" liver and blubber samples from the same animals. This provided an assessment of interlaboratory comparability on the same tissue homogenates and the comparability of the analyses of banked and the monitoring specimens collected from the same animals. This QA activity was an informal exercise only; the results have not been published.

In 1995 NIST, in collaboration with NOAA, formally instituted the National Marine Analytical Quality Assurance Program (NMAQAP). The mission of this program is to expand QA and specimen banking activities in marine environmental research and monitoring. To help accomplish the NMAQAP mission, a NIST satellite laboratory was established in Charleston, $\mathrm{SC}$, in association with the NOAA Center for Coastal Environmental Health and Biomolecular Research (CCEHBR). The NMMTB is housed both at the NIST-Gaithersburg and at the NISTCharleston facilities. NIST-Charleston provides the primary infrastructure for the marine mammal QA program and the NMMTB.

In 1997, an interlaboratory comparison exercise on trace elements in beluga whale liver sample splits was initiated among NIST-Gaithersburg, NWFSC, and the Texas A\&M University Veterinary Medical Center. All three laboratories were involved in analyzing marine mammal tissues collected in Arctic Alaska. For this exercise, sample splits of beluga whale liver tissues collected during the 1996 subsistence hunts in Alaska were provided to the participants, as well as the pilot whale liver control material (Whale Liver Homogenate I) and the new beluga whale liver control material (Whale Liver Homogenate II).

The 1999 exercise included only laboratories conducting organic analyses. The 10 participating laboratories (NIST-Gaithersburg, NIST-Charleston, CCEHBR, NWFSC, GERG, Mississippi State Chemistry Laboratory, University of Connecticut, National Lab for Environmental Testing [Canada], Ehime University [Japan], and University of Utah) measured PCB congeners and organochlorine pesticides in SRM 1945 and in the "unknown," Marine Mammal Blubber Control Material III (this material is described above in the control material section). Also in 1999, the program began holding meetings of participants in conjunction with the annual meeting of the Society of Environmental Toxicology and Chemistry (SETAC). 
Participation in the 2000 exercise included laboratories conducting both organic analyses (13 laboratories) and inorganic analyses (7 laboratories). The description and results of this exercise are presented in Parts 1 and 2 of this report. In 2001, there were approximately 21 laboratories participating in the organic exercise and 31 laboratories participating in the inorganic exercise. Expanding the number of laboratories provides an essential benefit for the participants in yielding higher quality consensus data. NIST also benefits from the preliminary concentration data and information gained on the candidate SRM materials that are routinely inserted into the exercises.

The QA program performs a major function in maintaining the quality of data resulting from the analysis of NMMTB specimens. Scientists requesting specimens from the bank for retrospective studies must demonstrate their analytical capabilities through appropriate QA activities, including participation in the NIST-administered QA program. In addition, NMFS requires that all researchers analyzing marine mammal tissues for contaminants under NMFS funding be participants in this program. This requirement ensures that the analytical results from marine mammal monitoring and research programs are of high quality and comparable.

\section{PART 1: DESCRIPTION AND RESULTS OF THE 2000 NIST/NOAA INTERLABORATORY COMPARISON EXERCISE PROGRAM FOR ORGANIC CONTAMINANTS IN MARINE MAMMAL TISSUES}

\section{Materials Used in the Exercise}

The exercise used two materials that were provided to 16 laboratories, of which 13 submitted data (Table 1.1). Participants were asked to make three measurements each on two materials: SRM 1945 Organics in Whale Blubber and "Marine Mammal Quality Assurance Exercise Control Material IV" (Control Material IV). Details on the preparation and certification of SRM 1945 are given in Schantz et al. (1995). The control material was prepared from blubber taken from a $350 \mathrm{~cm}$ female pilot whale. The animal stranded alive on the beach at Pea Island, NC $\left(35^{\circ} 69.228^{\prime} \mathrm{N} 75^{\circ} 48.359^{\prime} \mathrm{W}\right)$ and was euthanized on November 18, 1999 . Approximately 50 $\mathrm{kg}$ of blubber was excised, wrapped in aluminum foil, and shipped to the NIST Charleston Laboratory on February 18, 2000 inside a biological dry shipper. At NIST Charleston, the blubber tissue was stored in a liquid nitrogen $\left(\mathrm{LN}_{2}\right)$ vapor phase freezer at $-150{ }^{\circ} \mathrm{C}$ until prepared for this exercise. The material was trimmed on Teflon sheeting using a titanium knife. A total of $7 \mathrm{~kg}$ of trimmed blubber was placed in Teflon bags, which were heat sealed and shipped to NIST Gaithersburg for cryohomogenization according to established procedure (Zeisler et al., 1983). After homogenization, the material was placed inside a Teflon bag and blended manually by repeated inversion. The blended material was bottled as $12 \mathrm{~g}$ subsamples in glass jars and stored at $-80^{\circ} \mathrm{C}$. One bottle of this material along with one bottle of SRM 1945 were sent either on dry ice or using a biological dry shipper via overnight express to each participating laboratory. 
Table 1.1: Laboratories participating in the NIST/NOAA Interlaboratory Comparison Exercise Program for Organic Contaminants and Trace Elements in Marine Mammal Tissues.

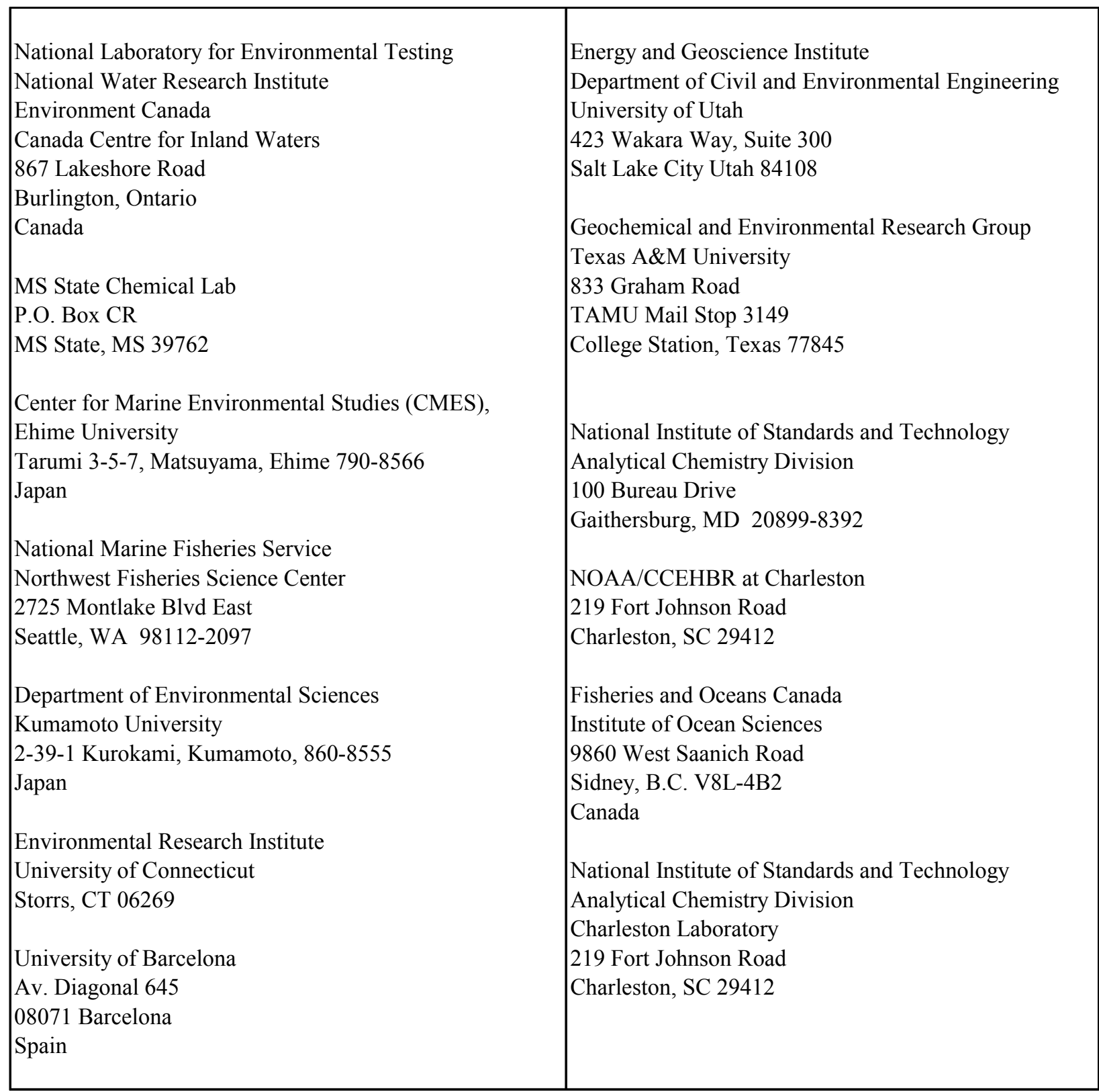

\section{Exercise Requirements and Target Analytes}

A suite of analytes was chosen for the exercise based on those used in the NIST/NOAA/NS\&T exercise and several additional analytes were included to broaden this list (Table 2.1). Laboratories were requested to make triplicate measurements of these compounds in each of the materials and report their data using a data template provided by NIST. Laboratories were also asked to provide results from additional analytes, such as coplanar PCBs or chlorobenzenes that 
were determined in the two materials. Results from the exercise were discussed during a workshop held in conjunction with the 2000 Society of Environmental Toxicology and Chemistry annual meeting held in Nashville, TN.

Table 2.1: Target analytes for the second annual NIST/NOAA Interlaboratory Comparison Exercise Program for Organic Contaminants and Trace Elements in Marine Mammal Tissues.

\begin{tabular}{|c|c|c|}
\hline Pesticides & PCB Congeners & Congener Substitution \\
\hline $2,4^{\prime}$-DDT & 18 & 2,2',5-trichlorobiphenyl \\
\hline 4,4'-DDT & 28 & 2,4,4'-trichlorobiphenyl \\
\hline $2,4^{\prime}-\mathrm{DDE}$ & 31 & 2,4',5-trichlorobiphenyl \\
\hline 4,4'-DDE & 44 & $2,2^{\prime}, 3,5^{\prime}$-tetrachlorobiphenyl \\
\hline 2,4'-DDD & 49 & $2,2^{\prime}, 4,5^{\prime}$-tetrachlorobiphenyl \\
\hline 4,4'-DDD & 52 & 2,2',5,5'-tetrachlorobiphenyl \\
\hline $\mathrm{HCB}$ & 66 & 2,3',4,4'-tetrachlorobiphenyl \\
\hline$\alpha-\mathrm{HCH}$ & 87 & 2,2',3,4,5'-tetrachlorobiphenyl \\
\hline$\gamma-\mathrm{HCH}$ & 95 & 2,2',3,5',6-tetrachlorobiphenyl \\
\hline$\beta-\mathrm{HCH}$ & 99 & 2,2',4,4',5-tetrachlorobiphenyl \\
\hline heptachlor epoxide & 101 & 2,2',4,5,5'-tetrachlorobiphenyl \\
\hline cis -chlordane & 105 & 2,3,3',4,4'-tetrachlorobiphenyl \\
\hline trans -chlordane & 118 & 2,3',4,4',5-tetrachlorobiphenyl \\
\hline oxychlordane & 128 & 2,2',3,3',4,4'-hexachlorobiphenyl \\
\hline cis -nonachlor & 132 & 2,2',3,3',4,6'-hexachlorobiphenyl \\
\hline trans -nonachlor & 138 & $2,2^{\prime}, 3,4,4^{\prime}, 5^{\prime}$-hexachlorobiphenyl \\
\hline dieldrin & 149 & 2,2',3,4',5',6-hexachlorobiphenyl \\
\hline mirex & 151 & $2,2^{\prime}, 3,5,5$ ',6-hexachlorobiphenyl \\
\hline & 153 & 2,2',4,4',5,5'-hexachlorobiphenyl \\
\hline & 156 & 2,3,3',4,4',5-hexachlorobiphenyl \\
\hline & 170 & 2,2',3,3',4,4',5-heptachlorobiphenyl \\
\hline & 180 & 2,2',3,4,4',5,5'-heptachlorobiphenyl \\
\hline & 183 & 2,2',3,4,4',5',6-heptachlorobiphenyl \\
\hline & 187 & 2,2',3,4',5,5',6-heptachlorobiphenyl \\
\hline & 194 & 2,2',3,3',4,4',5,5'-octachlorobiphenyl \\
\hline & 195 & $2,2^{\prime}, 3,3^{\prime}, 4,4^{\prime}, 5,6$-octachlorobiphenyl \\
\hline & 201 & $2,2^{\prime}, 3,3^{\prime}, 4,5,5^{\prime}, 6^{\prime}$-octachlorobiphenyl \\
\hline & 206 & $2,2^{\prime}, 3,3^{\prime}, 4,4^{\prime}, 5,5^{\prime}, 6$-nonachlorobiphenyl \\
\hline & 209 & 2,2', $3,3^{\prime}, 4,4^{\prime}, 5,55^{\prime}, 6,6^{\prime}$-decachlorobiphenyl \\
\hline
\end{tabular}




\section{Evaluation of the Exercise Results}

\section{Determination of Laboratory Analyte Means}

Each laboratory reported the results of their analyses (Sample 1, Sample 2, and Sample 3) and the mean for each laboratory was calculated. Non-numerical results were reported as "NA" (not analyzed). None of the target analytes were below the limit of detection for the participating laboratories (Tables 3.1-6.1 and Appendix A).

\section{Establishment of Consensus Values}

The following guidelines were used by NIST for establishing the "assigned values" or "consensus values" for the exercise. The consensus values for Control Material IV were the mean of all the reported laboratory means for a compound after the data were first screened by a Grubb's Single Iteration Outlier Test (Motulsky, 1997). Generally, most or all the values were included in the determination of the consensus value. The target values for the SRM were the certified values, reference values, or the consensus values from the 1999 exercise where SRM 1945 was also analyzed (Tables 5.1 and 6.1). In the NIST/NOAA/NS\&T exercise, the assigned values for the unknown material were calculated based on the performance of each laboratory on the SRM. If the laboratory was within $\pm 30 \%$ of the SRM value, their values for the corresponding unknown were used to determine the consensus value. This approach was not used in the present exercise for two reasons. First, if the SRM comparison method using $\pm 30 \%$ is used, nearly one-third of the data are excluded from the calculation of the control material consensus value. Relaxing the $\pm 30 \%$ criterion to $\pm 50 \%$ still results in the rejection of approximately $20 \%$ of the data that could be used to calculate the consensus value. Second, the concentration of Control Material IV was significantly greater than SRM 1945. For instance, the concentration of PCB 153 was 35 times greater in Control Material IV than in SRM 1945. Hence there was concern regarding the performance on the SRM being reflective of the performance on the control material.

\section{Reported Results}

Laboratories were assigned a numerical identification code based on the order in which data were received with the exception of NIST-Charleston, which is Laboratory 1. The same code was used for both materials. The results from the analysis of Control Material IV and SRM 1945 are summarized in Tables 3.1-6.1. Appendix A shows the tabulated results from the individual laboratories for both materials and the results are shown graphically in Appendix B. Appendix C gives the methods used for analysis by each laboratory and Appendix D shows data for additional analytes. 


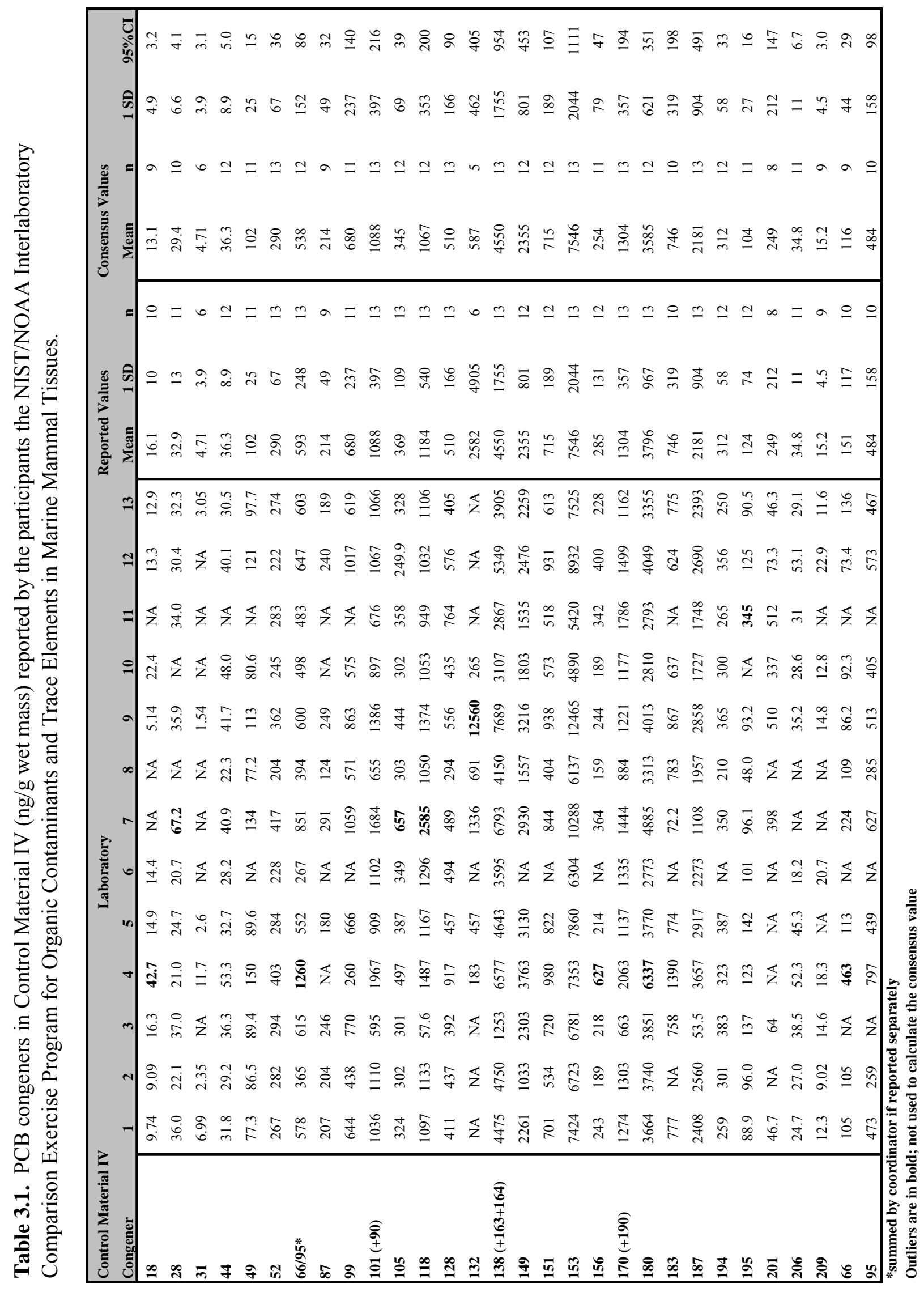




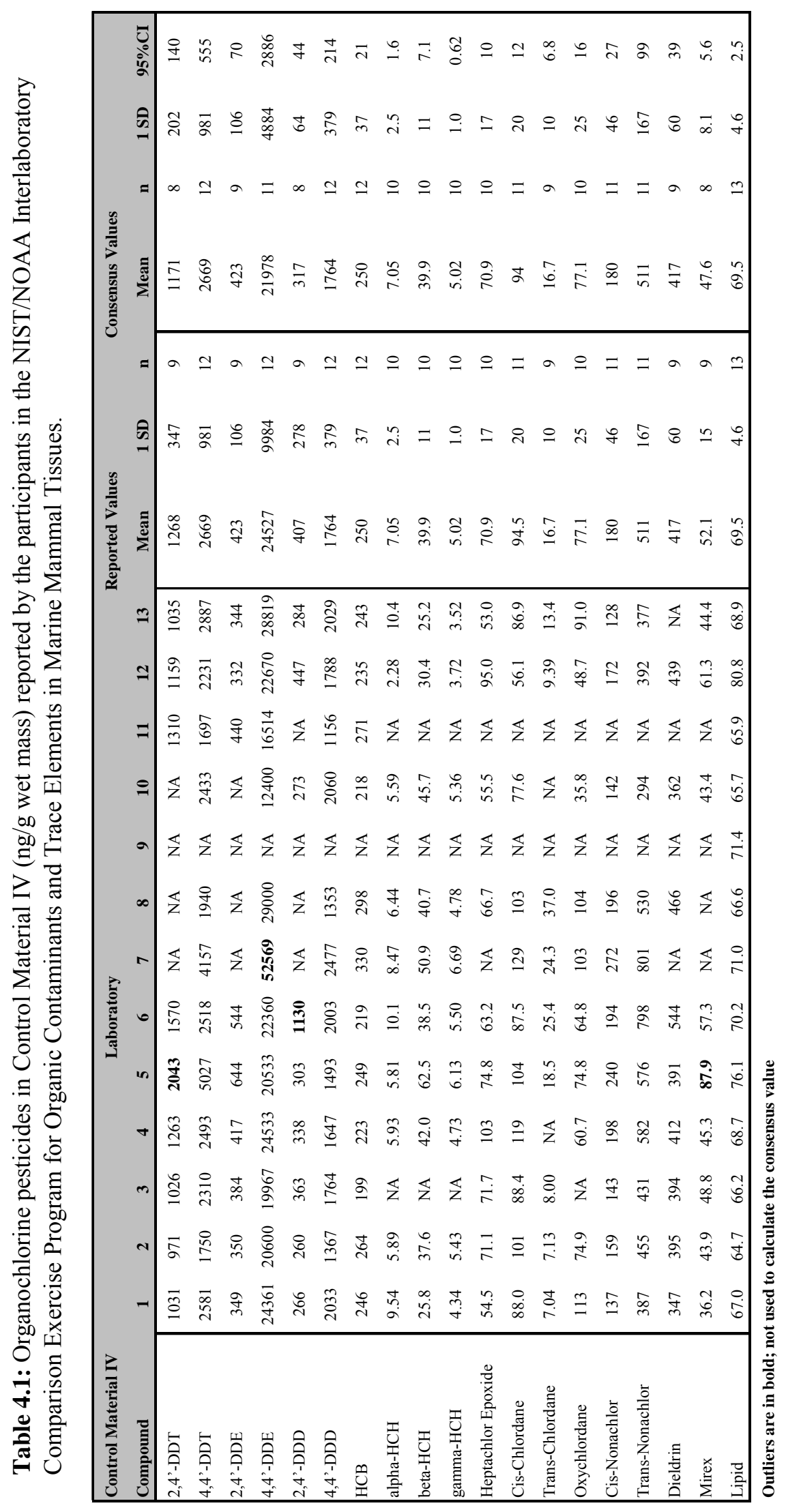




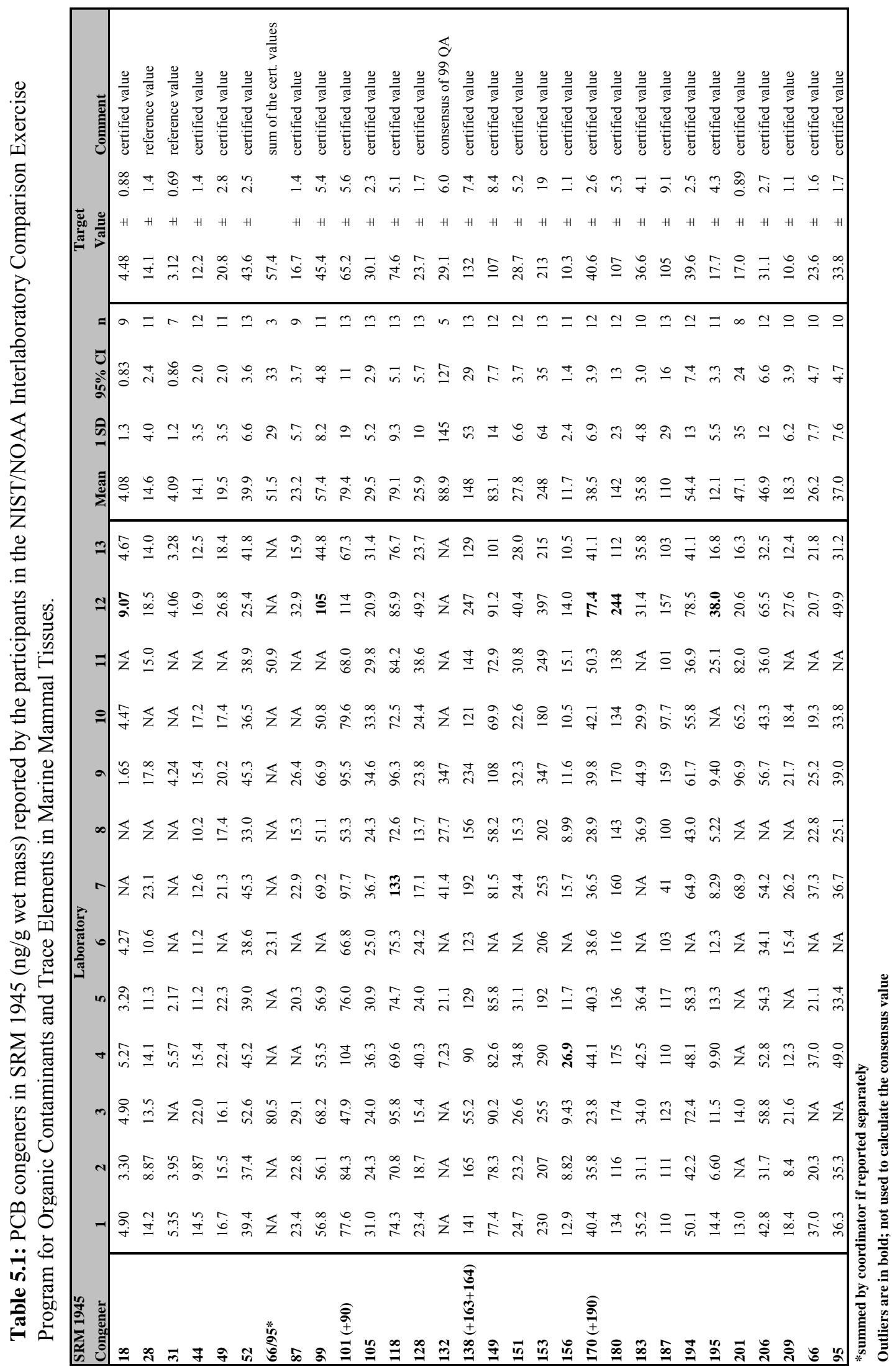




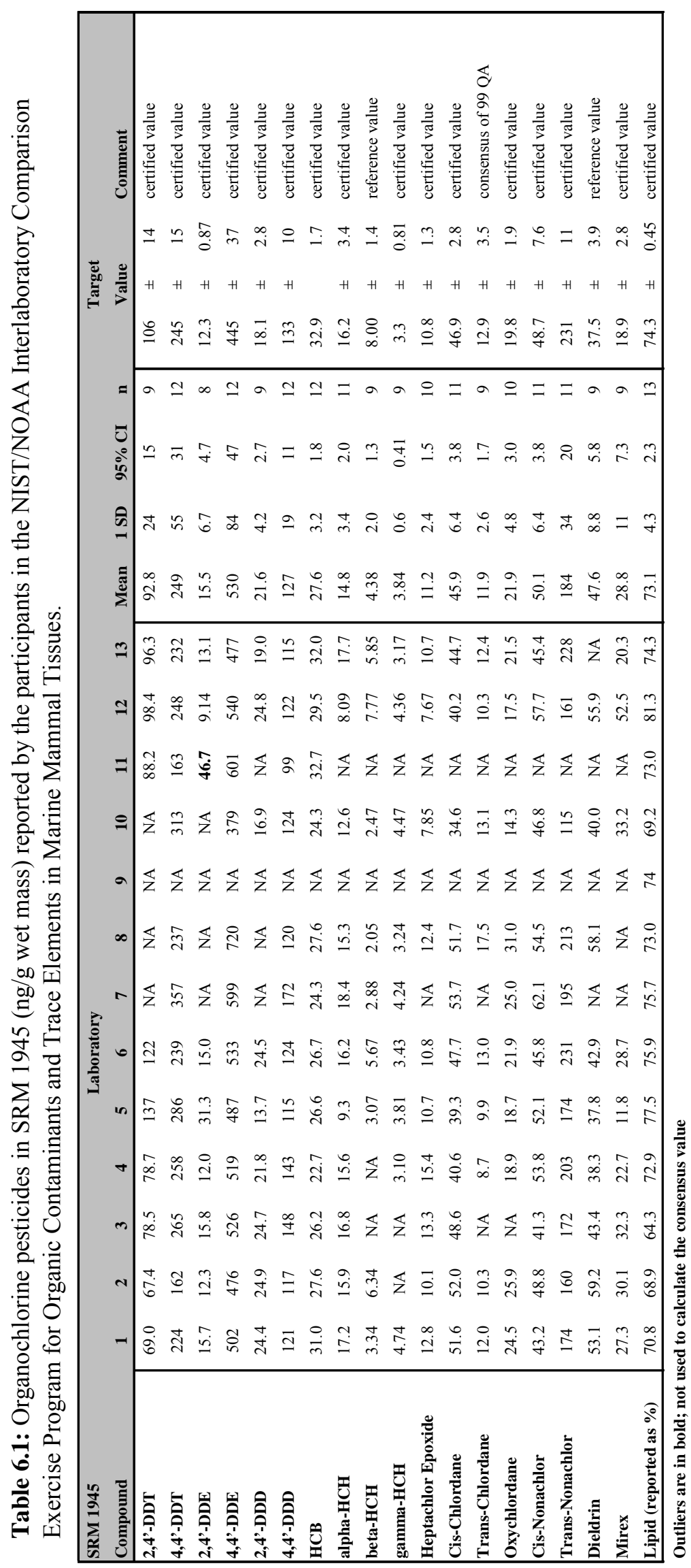




\section{Assignment of z-and p-scores}

Performance Scores: Different programs have different data quality needs. The acceptability of the results submitted by a laboratory will be decided by the individual program(s) for which the laboratory provides data. Typically, the program will use these exercise results in conjunction with the laboratory's performance in the analysis of certified reference materials and/or control materials, and of other quality assurance samples. These exercise results are shown in a number of ways in this report to aid in the evaluation of data quality.

IUPAC guidelines (IUPAC 1997) describe the use of "z-scores" and "p-scores" for assessment of accuracy and precision in interlaboratory comparison exercises, such as described in this report. These indices assess the difference between the result of the laboratory and the exercise assigned value, and can be used, with caution, to compare performance on different analytes and on different materials.

Accuracy Assessment (z-score):

$$
\begin{gathered}
\mathrm{z}=\text { bias estimate } / \text { performance criterion } \\
\text { or } \\
\mathrm{z}=(\mathrm{x}-\mathrm{X}) / \sigma
\end{gathered}
$$

where $\mathrm{x}$ is the individual laboratory result, $\mathrm{X}$ is the "Exercise Assigned Value," and $\sigma$ is the target value for the standard deviation. As described in the IUPAC guidelines, the choice of $\sigma$ is dependent upon the data quality objective of a particular program. It can be fixed or determined by reference to validated methodology (e.g., the calculated $\sigma$ from the exercise data, see Tables 3.1-6.1). The fixed performance criterion is more useful in the comparison of a laboratory's performance on different materials, while the use of the actual variation may be more useful within a given exercise, for example, if the determination of a particular analyte is more problematic than usual.

The z-scores calculated using both approaches and applied to each laboratory's data are given in Appendix A. The same criterion was adopted for use in this exercise as was used in the former NIST/NOAA/NS\&T program, where the target standard deviation was set to $25 \%$ of the exercise assigned value. The z-scores for the Control Material IV represent $25 \%$ of the assigned value so that $Z=+1$ is the assigned value plus $25 \%, Z=-1$ is the assigned value minus $25 \%$ and so forth. From a scientific point of view, IUPAC does not recommend the classification of z-scores, but does allow for such classification, e.g.,

$$
\begin{array}{ll}
|z| \leq 2 & \text { Satisfactory } \\
2 \leq|z| \leq 3 & \text { Questionable } \\
|z| \geq 3 & \text { Unsatisfactory }
\end{array}
$$


The tables in Appendix A summarize the results and performance indices including the number of analytes that fall within each category for each laboratory.

Precision Assessment (p-score):

$$
\mathrm{p}=\sigma_{\text {lab }} / \sigma_{\text {target }} \approx \mathrm{CV}_{\text {lab }} / \mathrm{CV}_{\text {target }}
$$

where $\sigma_{\text {lab }}$ and $\sigma_{\text {target }}$ are variance estimates for the individual laboratory and the target variance, respectively. The $\mathrm{CV}_{\text {lab }}$ is the coefficient of variance (or ratio of standard deviation to the mean), while the $\mathrm{CV}_{\text {target }}$ is a reasonable value chosen by the participants. During the workshop that accompanied this exercise, a $\mathrm{CV}$ of $15 \%$ was agreed upon, which is the same value used by the former NIST/NOAA/NS\&T program. Note that the precision that $p$ describes is that which occurs within a batch of analyses. Between batch variance is likely larger and was not assessed in this exercise.

\section{Results and Discussion}

Summarized results are shown in Tables 3.1-6.1. The concentration of many organochlorines in Control Material IV was considerably higher than in SRM 1945. The consensus value for the sum of PCB congeners in Control Material IV (Table 3.1) was 30,050 ng/g wet mass versus $1,393 \mathrm{ng} / \mathrm{g}$ wet mass in SRM 1945 (Table 5.1). Likewise the sum of the organochlorine pesticides in Control Material IV was 29,270 ng/g wet mass versus 1,446 ng/g wet mass in SRM 1945. 4,4'-DDE was present in the highest concentration in both samples with a consensus value of $21,141 \mathrm{ng} / \mathrm{g}$ wet mass in Control Material IV and certified value of $445 \mathrm{ng} / \mathrm{g}$ wet mass in SRM 1945. The levels observed in Control Material IV, while higher than SRM 1945, are typical of other delphinids from the North Atlantic Ocean (Kuehl et al., 1991). Lipid or "total extractable organics" $69.5 \% \pm 2.5 \%$ in Control Material IV (mean $\pm 95 \%$ confidence interval; Table 4.1 ) and the average value determined by the participants in SRM 1945 was $73.3 \% \pm 2.3 \%$ relative to the certified value of $74.3 \% \pm 0.45 \%$ (Table 6.1 ).

The relative scatter among the laboratories appeared similar for many of the compounds with some exceptions. All laboratories, with the exception of Lab 13 had difficulty obtaining the certified value for PCB 31 (Appendix B). This was evident by the large scatter in this plot. There was also considerable scatter among the laboratories for the values of PCB 31 in the Control Material IV. Laboratories also had difficulty agreeing on the value of PCB congener 201 , both for the control material and the SRM. This may be a result of the two nomenclature systems used for this PCB congener (Guitart et al., 1993). High biases (most values exceeding the certified value) were observed among the values determined in the SRM relative to the certified value for the following compounds: PCB 87, PCB 99, PCB 180, PCB 194, PCB 206, PCB 209, 4,4'-DDE, and mirex. Low biases (most values below the certified or reference value) were observed for PCB 149, PCB 195, HCB, $\beta-\mathrm{HCH}$, and trans-nonachlor.

A number of laboratories reported results for analytes in addition to the target compounds (Appendix D). Additional analytes that were reported included other PCB congeners (Labs 1, 2, 9, 10, and 12), coplanar PCBs (Labs 1 and 9), dioxins and furans (Lab 9), tris-(4-chlorophenyl) 
methane and methanol (Lab 8), and endosulfan II and nonachlor III (Lab 2). Interestingly, PCB 169 was found in Control Material IV in relatively high concentrations for a marine mammal tissue (e.g., Kuehl et al., 1991 and Berggrena et al., 1999). The concentration of PCB 169 in this material was determined to be $1.93 \mathrm{ng} / \mathrm{g}$ wet mass $\pm 0.040 \mathrm{ng} / \mathrm{g}$ wet mass by Lab 1 and $1.84 \mathrm{ng} / \mathrm{g}$ wet mass $\pm 0.048 \mathrm{ng} / \mathrm{g}$ wet mass by Lab 9. The concentration of PCB 169 (mean $\pm 95 \%$ confidence interval) in SRM 1945 was $0.21 \mathrm{ng} / \mathrm{g}$ wet mass $\pm 0.02 \mathrm{ng} / \mathrm{g}$ wet mass measured by Lab 1 and $0.13 \mathrm{ng} / \mathrm{g}$ wet mass to $0.15 \mathrm{ng} / \mathrm{g}$ wet mass measured by Lab 9 .

The participants used a variety of different methods to analyze the materials in this exercise (Appendix E). Six laboratories used Soxhlet extraction to extract the materials, two used pressurized fluid extraction, and the remaining laboratories used other techniques including sonication and column elution. Six laboratories performed a pre-separation on the sample extracts prior to $\mathrm{GC}$ analysis (i.e., fractionation), while seven did not. Most laboratories $(\mathrm{n}=8)$ used GC-ECD to quantify organochlorines, while five laboratories used GC-MS. Internal standards were used by eight laboratories, while four laboratories used external standards.

\section{Conclusions}

During the Nashville workshop there was some discussion regarding materials for future exercises. Blubber is typically the marine mammal tissue analyzed for organochlorine constituents; hence the program will continue to use this matrix. The exercise coordinators plan to vary the type of control material used to include other species of interest such as pinnepeds and delphinids. NIST is constrained somewhat on the choice of the material as a fairly large quantity $(\approx 1 \mathrm{~kg})$ is needed and this amount of material is not available on a routine basis. SRM 1945 will continue to be the SRM used in this exercise, since it is the only marine mammal tissue available with certified and reference values. This material also has had a number of other organochlorine compounds measured and reported, such as coplanar PCBs. The timing of the 2001 exercise will be similar to the 2000 exercise, with sample material distributed to the participants in April 2001 and the results due by October 26, 2001. A workshop to discuss the results will be held in conjunction with the 2001 SETAC meeting in Baltimore, Maryland, which is held from November 11-15, 2001. 


\section{PART 2: DESCRIPTION AND RESULTS OF THE 2000 NIST/NOAA INTERLABORATORY COMPARISON EXERCISE PROGRAM FOR TRACE ELEMENTS IN MARINE MAMMAL TISSUES}

\section{Materials Used in the Exercise}

Two whale liver homogenate materials and candidate SRM 1946 Lake Superior Fish Tissue were issued to the participating laboratories. Whale Liver Homogenate I (QC91LH1) was derived from liver tissues collected from Pilot whales stranded in 1990 on Cape Cod, MA (Wise et al., 1993). Similarly, Whale Liver Homogenate II (QC97LH2) was developed from liver tissue collected from Beluga whales taken in Alaska native subsistence hunts in 1996 at Point Lay, AK. This material served as the unknown for the exercise. Candidate SRM 1946 Lake Superior Fish Tissue was derived from the filleted tissue of Lake Trout (Salvelinus namaycush) collected from the Apostle Island region of Lake Superior through coordination with the Wisconsin Department of Natural Resources. All of the tissues were cryogenically pulverized and homogenized to provide powder-like materials as described above.

\section{Exercise Requirements and Target Analytes}

The seven participating laboratories (Appendix F, Table 1.2) were each sent $\approx 8 \mathrm{~g}$ of each of the above materials in frozen jars using liquid nitrogen vapor shippers. A letter of instructions for the exercise was included in the shipment along with a reprint of the manuscript containing NIST values for the exercise control material (QC91LH1) derived from instrumental neutron activation measurements (Wise et al., 1993). Each laboratory submitted data by email using a standard data template.

The following requirements were stipulated to the participants:

1. Analyze samples for core ( $\mathrm{Cd}, \mathrm{Cu}, \mathrm{Hg}, \mathrm{Fe}, \mathrm{Pb})$ and optional (Ni, Se, As, Zn, Ag) elements using accepted analytical procedures. Provide brief descriptions of sample preparation and analysis schemes.

2. Digest, process, and analyze five subsamples of QC97LH2

3. Digest, process, and analyze five subsamples of Candidate SRM 1946

4. Digest, process, and analyze three subsamples of QC91LH1

\section{Evaluation of the Exercise Results}

Establishment of Consensus Values

A set of guidelines was used by the NIST exercise coordinator to assign concentration (wet mass) values for each element in the "unknown" samples. First, the results for each element reported from the individual laboratories were evaluated by comparing their results for the QC91LH1 control sample against NIST-published data that were collected in 1991 using 
instrumental neutron activation analysis (INAA) and made available to each participating laboratory. Periodic reanalysis of this cryogenically stored material continues to show that the mass fractions of trace elements remain stable. These original measurements provided a good estimate of the concentration and range for each element in the QC91LH1 material, as jar-to-jar sample heterogeneity was incorporated into the uncertainty estimate and accuracy was verified with concurrent analyses of SRM 1577a Bovine Liver. A laboratory's result for a particular element was used if the difference between the reported mean for the participating laboratory and the mean of the INAA data differed by no more than $30 \%$. This criterion was not enforced for $\mathrm{Pb}$ as it was later determined that $\mathrm{Pb}$ was inhomogeneous in all three of the exercise materials. No data were rejected as outliers upon application of this criterion.

A consensus mean (derived from a "mean of laboratory means" determination) for each element in each sample was established once the laboratory means and $95 \%$ confidence intervals were computed. The $95 \%$ confidence limits (in subsequent tables) and corresponding error bars (in subsequent graphs) are expressed as $\pm \mathrm{ts} / \mathrm{V}_{\mathrm{n}}$. The raw laboratory results and summary statistics are tabulated in Appendix G, Table 2.2. The corresponding consensus mean summary statistics are located in Table 3.2 in Appendix H. Consensus mean plots for each reported element in the unknown samples (QC97LH2 and SRM 1946) are given in Appendix I. The consensus mean data was used in conjunction with z-scores to evaluate laboratory performance.

\section{Assignment of z-and p-scores}

A discussion on the assignment of $\mathrm{z}$ - and p-scores and their classification categories can be found in Part 1 of this report. The performance criteria used for the trace element component of the exercise were different than the criteria used in the organic contaminants exercise and are discussed subsequently. For the trace elements exercise, z-scores were calculated using a target standard deviation $(\sigma)$ of $\pm 10 \%$ of the consensus mean. For example, for $z= \pm 1$ or $z= \pm 2$ the result would be $10 \%$ or $20 \%$ higher (or lower) than the consensus mean, respectively. Z-scores should be used to comment on relative and not absolute concentration accuracy, which is considered in the next section. With this caveat, z-scores can be classified into the three categories described in Part 1 to assess the performance of each laboratory. Using a "fixed" performance criterion offers a way for each laboratory to compare their performance on different samples. It should be recognized that any particular laboratory might have a detection limit or analytical method deficiency for a particular analyte. For marine mammal analyses, the acceptability of a particular laboratory's results should be judged in the context of the data quality needs of a particular program. The z-score results for the QC97LH2 and SRM 1946 samples are displayed in Appendix J, in both tabular (Table 4.2) and graphical format.

The external repeatability of each laboratory for individual elements was assessed using a pscore where laboratory repeatability (coefficient of variation) was normalized to an assigned target value for the coefficient of variation. The value for $\mathrm{CV}_{\text {Target }}$ was fixed at $10 \%$ for the trace elements exercise. For example, for $\mathrm{p}= \pm 0.5$ or $\mathrm{p}=1.2$ the laboratory repeatability would be $5 \%$ or $12 \%$, respectively. The p-score results for the QC97LH2 and SRM 1946 samples are displayed in Appendix $\mathrm{J}$, in Table 5.2. 


\section{Normalization Factors}

Interlaboratory comparability helps each participating laboratory demonstrate method validity, but method accuracy cannot necessarily be inferred by comparability alone. Ideally, if the exercise includes a relatively large number of participants (e.g., >20), the consensus mean should provide an unbiased estimate of the true mean. However, when the number of participating laboratories is low, the consensus mean value may be skewed by the results from one or two laboratories, making it a less useful benchmark for assessing laboratory performance. As the number of participating laboratories, and correspondingly, the number of analytical methods increase, biases from multiple independent methods will tend to cancel and the consensus mean should provide a more useful benchmark.

It was difficult to assess method accuracy in this round-robin exercise from the consensus data, because of the relatively small number of participating laboratories $(n=7)$, so normalization factors computed from the QC91LH1 control data were employed to test the robustness and accuracy of each laboratory's analytical method as applied to the unknown samples. The assumption of method robustness and accuracy was challenged because success or failure in determining a suite of elements in a particular sample matrix cannot be assumed if the sample matrix changes significantly.

The computation of normalization factors was based on the assumption that the mean of the NIST values generated in the Gaithersburg and Charleston laboratories using two independent techniques (INAA and standard additions ICPMS) provided a good estimate of the "true" concentration values of elements in the control sample. Subsequently, the control data generated by each laboratory was normalized to this "true" value as a quotient:

$$
\text { Normalization Factor }=\frac{\text { Lab Mean }}{\text { True Value }}
$$

Normalization factors were computed for each element analyzed in the control material and normalized laboratory means for the unknown samples were generated by dividing the original laboratory mean by the normalization factor. Thereafter, new consensus mean and standard deviation data were generated and compared to the original consensus data. This comparison was performed to determine if the standard deviation of the consensus mean would be reduced after normalization. If an improvement in the standard deviation occurred, the correction factor was warranted, implying that the normalized consensus mean provided a better method accuracy benchmark. If the standard deviation of the consensus mean increased after normalization, the correction factor was not warranted and normalized data would not provide a useful benchmark for method accuracy. Appendix K, Table 6.2 lists the normalization factors computed for the element suite analyzed by each participating laboratory and Table 7.2 lists the normalized consensus mean and summary statistics, along with the results of the correlation tests for the unknown QC97LH2 and SRM 1946 samples. 


\section{Error Assessment}

Sources of error in interlaboratory comparison exercises can be assessed with a two-sample Youden Plot (Youden, 1959). Figure 2.1 illustrates how a Youden plot can be used to provide information on the occurrence of indeterminate (random) and determinate (systematic) errors, if the concentrations of the analytes are similar in both samples. Results will tend to group at random around the intersection of the consensus means if indeterminate errors are occurring (Fig. 2.1a). Determinate errors lead to bias in a measurement technique. Typical sources of determinate errors are calibration errors, blank correction errors and analytical method errors such as analyte volatility (loss) and contamination. Results will tend to group about a line running from the origin through the intersection of the consensus mean if determinate errors are occurring. This phenomenon is illustrated in Fig. 2.1b in the lower left and upper right quadrants of the Youden plot. Youden plots (Appendix L) were generated for elements analyzed in the QC91LH1 and QC97LH2 samples, if more than three laboratories reported results. Ninety-five percent confidence regions $( \pm$ ts $/ \sqrt{ } \mathrm{n})$ were centered on the intersection of the laboratory means and superimposed on the intersection of the consensus means, so that the significance of the deviation from the consensus values could be judged.

Figure 2.1. Using Youden plots for error assessment.

Indeterminate Errors

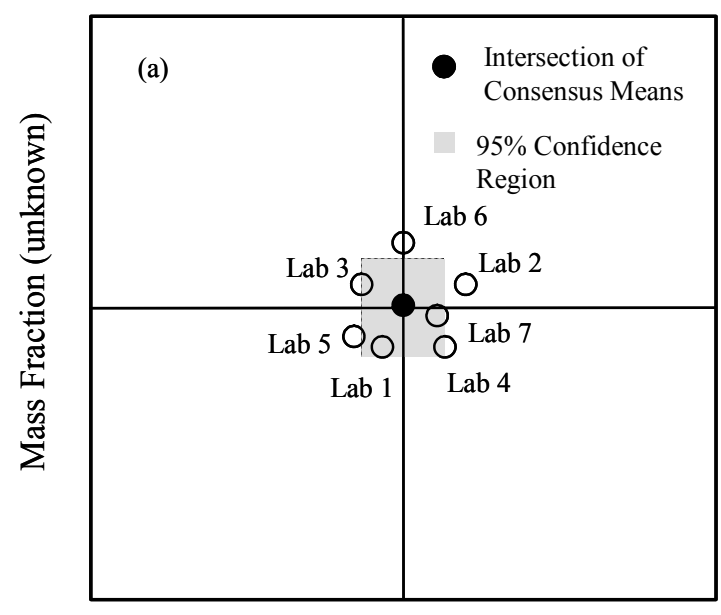

Mass Fraction (Control)
Determinate Errors

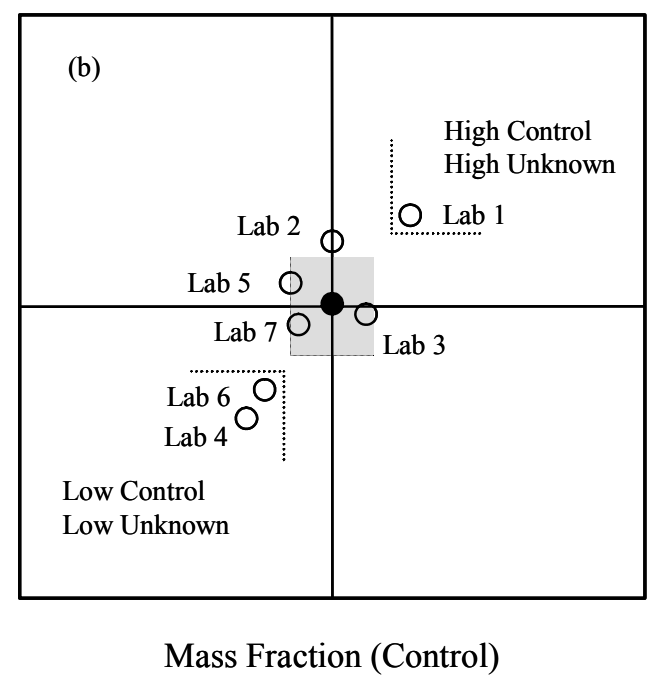

\section{Results and Discussion}

The participants used several different methods to analyze the materials in this exercise, depending on the element: inductively coupled plasma mass spectrometry (ICPMS), inductively coupled plasma optical emission spectroscopy (ICP-OES), flame, furnace and cold-vapor atomic absorption spectroscopy (AAS), and instrumental neutron activation analysis (INAA). The NIST 
laboratory in Charleston, SC used ICPMS and the method of standard additions for all elements except $\mathrm{Hg}$, which was determined using cold vapor isotope dilution ICPMS. The Nuclear Methods group at NIST performed the INAA analyses.

Data for the full element suite $(\mathrm{Cd}, \mathrm{Cu}, \mathrm{Hg}, \mathrm{Fe}, \mathrm{Pb}, \mathrm{Ni}, \mathrm{Se}, \mathrm{As}, \mathrm{Zn}$, and $\mathrm{Ag})$ are reported in tabular form in the Appendices, where possible. However, consensus data plots, z-plots, and Youden diagrams were only generated for $\mathrm{Cd}, \mathrm{Cu}, \mathrm{Hg}, \mathrm{Fe}, \mathrm{Pb}, \mathrm{Se}$ and $\mathrm{As}$ due to an insufficient number of reporting laboratories for $\mathrm{Ni}, \mathrm{Zn}$, and $\mathrm{Ag}$. Accordingly, the results for $\mathrm{Ni}, \mathrm{Zn}$, and Ag are of limited value and will not be discussed further.

\section{z- and p-scores}

The z-plots (Appendix J) for QC97LH2 or SRM 1946 show that subgroups of the exercise participants have demonstrated comparability within the $|0-2|$ z-range for most elements regardless of the sample, using $10 \%$ of the consensus mean as the performance criterion. This $\mathrm{z}$ score range implies that a laboratory in this subgroup can distinguish between two samples when their respective analyte concentrations differ from $0 \%$ to $40 \%$. It should be expected that the $\mathrm{z}$ scores of greater than $\mathrm{z}= \pm 1$ should occur with greater frequency for the SRM 1946 sample, as the analyte concentrations for certain elements are 1 to 2 orders of magnitude lower than their respective levels in the QC97LH2 sample. The frequency of higher p-scores for the SRM 1946 sample can be rationalized using the same argument. The fact that sample inhomogeneity may be a limiting factor when evaluating p-scores (i.e., intralaboratory repeatability) should not be ignored. In fact, comparing the large variation in $\mathrm{p}$-scores for $\mathrm{Pb}$ with those of other elements across the laboratories suggests $\mathrm{Pb}$ inhomogeneity in the samples.

\section{Normalization Procedures}

The z-score method fundamentally cannot address the absolute accuracy of consensus data unless a lack of bias in the analytical data that yields the consensus value is verified. Application of the normalization procedure to the consensus data provided a means to assess the accuracy of the consensus data by linking individual measurements (and methods) from a participating laboratory to a "true" value. Ideally, the "true" value would be derived from a NIST SRM, so that confidence would be implied and agreed upon by all laboratories. In the absence of this situation, the results determined by NIST for the pilot whale liver control sample (QC91LH1) using standard additions ICPMS and INAA analysis were combined. The comparison test results from the normalization procedure (Appendix K) indicated that the standard deviation of the consensus value could be improved for $\mathrm{Cu}, \mathrm{Hg}, \mathrm{Fe}$, and $\mathrm{As}$ in QC97LH2 and $\mathrm{Hg}, \mathrm{Fe}$, and As in candidate SRM 1946. The normalization procedure did not lower the standard deviation of the consensus value for $\mathrm{Se}$ in either of the samples or $\mathrm{Cu}$ in SRM 1946. This implies that the laboratory performance on the control standard was not correlated with the performance on the unknown sample, suggesting that the robustness of a particular method used in one or more of the laboratories was questionable. For example, this may be related to a method detection limit phenomenon for $\mathrm{Cu}$. Referring to Table 6.2 in Appendix $\mathrm{K}$, the "true" concentration of $\mathrm{Cu}$ in the control material (QC91LH1) is $3.26 \mathrm{mg} / \mathrm{kg}$. In QC97LH2 (Table 7.2), normalization improves the consensus standard deviation and yields a normalized consensus value of $12.8 \pm 0.853$ $\mathrm{mg} / \mathrm{kg}$, compared to an original consensus value of $13.1 \pm 1.22 \mathrm{mg} / \mathrm{kg}$ in Table 3.2. However, in 
SRM 1946, normalization worsens the consensus standard deviation and yields a consensus value of $0.450 \pm 0.212 \mathrm{mg} / \mathrm{kg}$, compared to an original consensus value of $0.473 \pm 0.204 \mathrm{mg} / \mathrm{kg}$ in Table 3.2. The $\mathrm{Cu}$ concentration in SRM 1946 is an order of magnitude lower than the concentration of $\mathrm{Cu}$ in the control material, so good performance on the control material (a normalization factor approaching unity) does not infer similar success for SRM 1946. Similarly, the Se results suggest a matrix effect rather than a detection limit phenomenon for Se.

\section{Youden Diagrams}

Youden plots (Appendix L) for Cd, As and Se indicate the presence of indeterminate errors only. The results for As and Se were encouraging because two of the laboratories used ICPMS as the analytical procedure, where determinations involving these elements are often problematic. The INAA methods used by NIST for $\mathrm{Cu}$ (Laboratory 2) seemed to produce a low value for the QC91LH1 and QC97LH2 samples that was significantly different from the consensus data, while Laboratory 4 produced a high Fe value for the QC91LH1 and QC97LH2 samples. The most complete data set was reported for $\mathrm{Hg}$, which indicated random errors for all laboratories with the possible exception of Laboratory 5, which produced a low value for the QC91LH1 and QC97LH2 samples. Youden plots were not generated for QC91LH1 and SRM 1946 because of the large differences in trace element concentration.

\section{Methylmercury Data}

One of the laboratories reported data for methylmercury in the three materials: QC91LH1 (1.422 $\mathrm{mg} / \mathrm{kg} \pm 0.074 \mathrm{mg} / \mathrm{kg}, \mathrm{n}=12)$, QC97LH2 $(1.296 \mathrm{mg} / \mathrm{kg} \pm 0.074 \mathrm{mg} / \mathrm{kg}, \mathrm{n}=22)$ and SRM 1946 $(0.304 \mathrm{mg} / \mathrm{kg} \pm 0.024 \mathrm{mg} / \mathrm{kg}, \mathrm{n}=17)$. The latter data may prove useful for comparison with methylmercury data produced by the methods that are used in the value assignment and certification process for methylmercury in SRM 1946.

\section{Conclusions}

Several rounds of the exercise will be required to fully assess the state of the practice of trace element measurements in marine mammals. Incorporation of more laboratories will also be important, as an increased sample size will serve to improve the analytical results and utility of any future exercises. Some of the participants have expressed the desire to incorporate analysis of an SRM into the exercise (at the expense of the participant) for the purposes of method validation. This and other comments are being considered to improve the QA model for 2001 and beyond. Increasing participation nationally and internationally, and possibly incorporating a NIST SRM into the exercise, will allow for a more robust outlier rejection scheme to be employed. This aspect is important to consider so that more informative data can be disseminated back to the exercise participants. Increasing laboratory participation will also help NIST gain access to more reliable consensus values for the candidate SRM materials that are distributed in the exercises, providing a secondary benefit from the QA program. It is projected that the 2001 trace elements exercise will have 30 participating laboratories, including 12 international laboratories. 


\section{LITERATURE CITED}

Becker, P. R., Wise, S. A., Schantz, M. M., Koster, B. J., and Zeisler, R. “Alaska Marine Mammal Tissue Archival Project: Sample Inventory and Results of Analyses of Selected Samples for Organic Compounds and Trace Elements," Rep. No. NISTIR 4731. U.S. Dept. of Commerce. (1992).

Berggrena, P., Ishaq, R., Zebür, Y., Näf, C., Bandh, C., and Broman, D. Patterns and Levels of Organochlorines (DDTs, PCBs, non-ortho PCBs and PCDDs/Fs) in Male Harbour Porpoises (Phocoena phocoena) from the Baltic Sea, the Kattegat-Skagerrak Seas and the West Coast of Norway. Mar. Pollut. Bull. 38, 1070-1084. (1999).

Cantillo, A. Y. and Parris, R.M. National Status and Trends Program Quality Assurance Project: Trace Organic Intercomparison Exercise Results 1989-1990, NOAA Tech. Memo. NOS/ORCA 69 (1990)

Cantillo, A. Y. and Parris, R. M. "Evaluation of Trace Organic NOAA Status and Trends Quality Assurance Project Performance," in Quality Assurance for Analytical Laboratories, M. Parkany (ed.), Royal Society of Chemistry, M. Parkany (ed.), Royal Society of Chemistry, Special Publication No. 130 (1993)

Cantillo, A. Y. NS\&T Quality Assurance Project Intercomparison Results 1991-1995, NOAA Tech. Memo. 79 NOA/ORCA (1995).

Guitart, R., Puig, P., and Gomez-Catalan, J. Requirement for a Standardized Nomenclature Criterion for PCBs: Computer-Assisted Assignment of Correct Congener Denomination and Numbering. Chemosphere 27, 1451-1459. (1993).

IUPAC "The International Harmonized Protocol for the Proficiency Testing of (Chemical) Analytical Laboratories," Pure \& Appl. Chem. 65, 123-2144. (1993).

Kuehl, D. W., Haebler, R., and Potter, C. Chemical Residues in Dolphins from the U.S Atlantic Coast Including Atlantic Bottlenose Obtained During the 1987/1988 Mass Mortality. Chemosphere 22, 1071-1084. (1991).

Motulsky, H. Grubbs' Test for Detecting Outliers. GraphPad Insight. Issue 14 (1997).

Schantz, M. M., R. M. Parris, S.A. Wise, H. T. Won, and Turle, R. Polychlorinated biphenyl (PCB) congeners and chlorinated pesticides in a cod liver reference material. Chemosphere 24, 1687-1698 (1992.)

Schantz, M. M., Koster, B. J., Wise, S. A., and Becker, P. R. Determination of PCBs and Chlorinated Hydrocarbons in Marine Mammal Tissues. Sci. Total Environ. 139/140, 323345. (1993). 
Schantz, M. M., Koster, B. J., Oakley, L. M., Schiller, S. B., and Wise, S. A. Certification of Polychlorinated Biphenyl Congeners and Chlorinated Pesticides in a Whale Blubber Standard Reference Material. Anal. Chem. 34, 901-910. (1995).

Schantz, M. M., Wise, S. A., Segstro, M., Muir, D. C. G., and Becker, P. R. Interlaboratory Comparison Study for PCB Congeners and Chlorinated Pesticides in Beluga Whale Blubber. Chemosphere 33, 1369-1390. (1996).

Schantz, M. M., Demiralp, R., Greenberg, R. R., Hays, M. J., Parris, R. M., Porter, B. J., Poster, D. L., Sander, L. C., Sharpless, K. S., Wise, S. A., and Schiller, S. B. Certification of a Frozen Mussel Tissue Standard Reference Material (SRM 1974a) for Trace Organic Constituents. Fresenius J. Anal. Chem. 358, 431-440. (1997).

Schantz, M. M., Porter, R. M., and Wise. S. A. NIST/NOAA NS\&T Intercomparison Exercise Program for Organic Contaminants in the Marine Environment. Description and Results of 1999 Organic Intercomparison Exercise. NOAA Tech. Memo. 146 NOA/ORCA (1999).

Wise, S. A., Schantz, M. M., Koster, B. J., Demiralp, R., Mackey, E. A., Greenberg, R. R., Burow, M., Ostapczuk, P., and Lillestolen, T. I. Development of Frozen Whale Blubber and Liver Reference Materials for the Measurement of Organic and Inorganic Contaminants. Fresenius J. Anal. Chem. 345:270-277. (1993).

Wise, S. A. Quality Assurance of Contaminant Measurements in Marine Mammal Tissues. Coastal Zone 93: Proceedings of the 8th Symposium on Coastal and Ocean Management (New Orleans, LA), O.T. Magoon, W.S.Wilson, H. Converse, and L.T. Tobin, editors. ASCE, New York, NY. 3,2531-2541 (1993).

Youden, W. J. Graphical Diagnosis of Interlaboratory Test Results. Ind. Quality Control. 15: 2429 (1959).

Zeisler, R., Langland, J. K., and Harrison, J. K. Cryogenic Homogenization Procedure for Biological Tissues. Anal. Chem. 60: 2760-2765. (1983). 